The degree of coincidence in the development of VAM-infection intensity and phosphorus-absorption differences was determined in a study whereby the disturbance effect was established from an initially disturbed soil. These measurements were made on plants which had grown in disturbed soil which was then allowed to remain undisturbed over several cycles of corn growth, and also on plants grown in soil which was repeatedly disturbed. A coincidental evolution of mycorrhizal infection intensity and phosphorus-absorption differences between disturbed and undisturbed treatments was found. Such a correlation is a requirement of our hypothesis. We accepted our hypothesis based upon the above evidence.

\title{
A new automatic electrolytic respirometer
}

\author{
H. T. Tribe \\ Department of Applied Biology, The University, Pembroke Street, Cambridge \\ CB2 3DX, U.K. \\ and

\section{P. Maynard} \\ Institute of Biotechnology, The University, Downing Street, Cambridge CB2 3EF, \\ U.K.
}

The electrolytic method for measuring oxygen uptake in biological systems has a long history. Macfadyen (1961) states that it goes back to 1923, when Fernandes used it for studies with germinating peas. The method has been used in many forms, most of which have been difficult to adapt to more than a few replicates and have required a great deal of attention. For these reasons its full potential has not yet been realised. The basic principle is the enclosure of a biological system within an airspace which is connected to the anodic limb of an electrolysis cell suitable for generating oxygen. Uptake of oxygen by the system reduces the pressure in the airspace such that electrical contact is made between the anode and the electrolyte, and oxygen is supplied to the system. When pressure is restored in the airspace, contact between the anode and electrolyte is broken. Further oxygen uptake causes contact to be made again, and the cycle repeats. Carbon dioxide is absorbed in a vessel of alkali placed within the system and has only a transient influence on pressure in the airspace. The temperature of the system must be kept constant.

The volume of oxygen supplied to the system is measured in one of two ways. The simpler to arrange, but cumbersome and impossible to automate, is the collection of hydrogen gas from the cathodic limb of the electrolysis cell. This has the further disadvantage that this limb must be "open" to the atmosphere and barometric pressure must be taken into consideration. The better alternative is to measure the current required to supply the oxygen and to calculate, from Faraday's laws, the oxygen delivered. Combinations of ammeters and recorders have been used, but 
considerable technical expertise and facilities have been necessary to work with these. They have the advantage that the electrolytic copper cell may be used and the respirometer be of the "closed" type, operating independently of atmospheric pressure. Electrical recording of oxygen uptake has been associated primarily with entomological studies using electrolytic respirometers; examples are given by Macfadyen (1961) and Chase et al. (1968).

In soil studies, hydrogen collection has been used almost exclusively, beginning with Swaby \& Passey (1953), up to the respirometer of Manios \& Balis (1983). That of Birch \& Friend (1956) was reasonably simple, and was given prominence in Hesse's textbook (1971) for measurement of organic matter decomposition. However, no technique making use of an electrolytic respirometer was given in the influential Methods of Soil Analysis of the American Society of Agronomists (Page 1982).

The electrolytic respirometer is in principle ideal for studying oxygen uptake from aerobic soil systems, especially now that the evolution of the microcomputer has enabled recording of electrical currents to be almost fully automated. We have developed a respirometer made up of three sets of components:

(1) the Respirometer Units, each comprising a sample container, electrolytic cell and a compensator vessel;

(2) the Electronic Control Unit, which supplies electrical potential to the electrodes of the respirometer units, measures the current required to supply oxygen to each respirometer unit and sends the data to the microcomputer;

(3) the Recording System: BBC Microcomputer, disc drive, visual display unit and printer.

Up to thirty-two respirometer units may be simultaneously monitored by the Maynard Projects MP 686-32 Electronic Control Unit, and up to 128 units by the MP 686-128 Model. The electronic control unit is run by a Programme Disc, and measurements of current are recorded on a Data Collection Disc at intervals decided by the experimenter. These measurements, calibrated directly in ml oxygen at NTP, may be printed out as required, or put on the visual display unit in graphical form and then printed (see Tribe 1988, fig. 4). When the respirometer is running, a continuous record of the progress of oxygen uptake in each respirometer unit is given on the VDU screen.

Various types of respirometer unit are compatible with the MP 686 Electronic Control Unit. Our Standard Respirometer Unit, based on the soil leaching tube used in the Soils Laboratory of the University Department of Applied Biology, is illustrated to scale in Figure 1. It consists of the leaching tube AA, containing a soil sample B, on which stands a "bijou" tube with $5 \mathrm{ml}$ of $2 \mathrm{M}$ sodium hydroxide, $\mathrm{C}$. The space above the soil is enclosed and into the space projects a glass tube $D$, on to which fits the cap of a polystyrene test tube, $\mathrm{E}$. The test tube contains molar sulphuric acid saturated with excess copper sulphate and constitutes the electrolysis cell. A copper cathode, $\mathrm{F}$, is immersed in the electrolyte and a platinum anode, $\mathrm{G}$, is arranged so that it just touches the surface of the electrolyte. The anode wire passes through the glass tube, $\mathrm{H}$, and the Suba Seal cap, I. The cathode wire passes through the glass tube, D, up one limb of an inverted Y-piece and through the Suba Seal cap, J. A compensator bottle, $K$, of approximately the same air volume as that in the space above the soil, is fitted to the other limb of the $\mathrm{Y}$-piece. The anode and cathode wires lead, via a connector strip, to the MP 686 Electronic Control Unit. The 


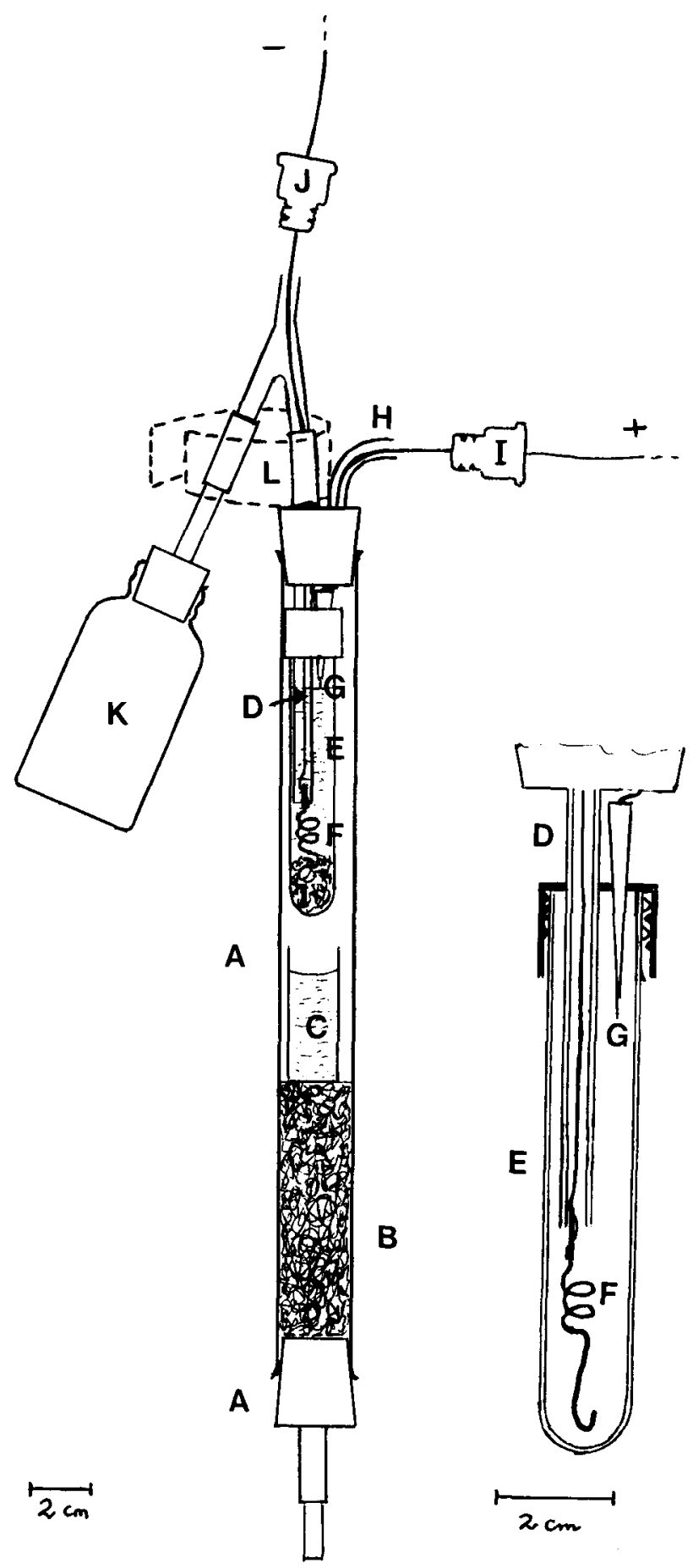

Figure 1. Standard Respirometer Unit; inset shows electrolysis cell; both to scale; note different scale bars. 
connector strip is attached to a rack which holds up to sixteen respirometer units in a temperature-controlled water bath.

The respirometer units are temperature equilibrated by partial submersion in the water bath such that Tubes $\mathrm{H}$ are above water level, with Suba Seal caps I and $\mathbf{J}$ loose on the wires. Lead weights, L, keep the units in the water. The caps are then pushed on to their connections, the units finally submerged, electrical connection made with the control unit and recordings begin.

Generation of small quantities of ozone has been reported in certain electrolytic respirometers, especially on the passing of relatively high currents (Woodland 1973). Woodland removed ozone under these conditions by use of the ozone catalyst nickel di-N-butyl-dithiocarbamate. We have made no analyses for ozone, traces of which are unlikely to influence decompositions occurring within soil samples. Further, the very low carbon dioxide concentrations which may occur in the atmosphere of respirometers whose sample chambers are exposed to caustic alkali is likely to have only a minor effect on the rate of decomposition occurring within a soil sample where carbon dioxide is continually produced.

From the studies on hair decomposition in soil (Tribe 1988), the predominating influence on respiration in soil samples is the soil structure, which governs the pore system controlling the exchange of gases between the soil matrix and the air above the soil.

A fuller account of the soil respirometer will be published in The Mycologist. The Electronic Control Units and the Standard Respirometer Units are now available for purchase; for information, contact the authors.

\section{References}

Birch, H. F. \& Friend, M. T. 1956. Humus decomposition in East African soils. Nature, London 178, $500-501$.

Chase, A. M., Unwin, D. M. \& Brown, R. H. J. 1968. A simple electrolytic respirometer for the continuous recording of oxygen consumption under constant and natural conditions. Journal of Experimental Biology 48, 207-215.

Hesse, P. R. 1971. A textbook of soil chemical analysis. London: Murray.

Macfadyen, A. 1961. A new system for continuous respirometry of small air-breathing invertebrates under near-natural conditions. Journal of Experimental Biology 38, 323-341.

Manios, V. \& Balis, C. 1983. Respirometry to determine optimum conditions for the biodegradation of extracted olive press-cake. Soil Biology Biochemistry 15, 75-83.

Page, A. L. (editor-in-chief) 1982. Methods of soil analysis, 2nd edn, Vol 2: Chemical and microbiological properties. Madison, Wisconsin: American Society of Agronomy.

Swaby, R. J. \& Passey, B. I. 1953. A simple macro-respirometer for studies in soil microbiology. Australian Journal of Agricultural Research 4, 334-339.

Tribe, H. T. 1988. Colonisation of hair in disturbed soils. Proceedings of the Royal Society of Edinburgh 94B, $109-117$.

Woodland, D. J. 1973. The ozone problem in electrolytic respirometry and its solution. Journal of Applied Ecology 10, 661-662. 